\title{
Role of glucagon-like peptides in inflammatory bowel diseases-current knowledge and future perspectives
}

\author{
Hubert Zatorski ${ }^{1}$ - Maciej Sałaga ${ }^{1} \cdot$ Jakub Fichna $^{1}$ \\ Received: 5 March 2019 / Accepted: 15 July 2019 / Published online: 29 July 2019 \\ (C) The Author(s) 2019
}

\begin{abstract}
Inflammatory bowel diseases (IBD), including Crohn's disease (CD) and ulcerative colitis (UC), are chronic, relapsing, intestinal inflammatory disorders with complex and yet unrevealed pathogenesis in which genetic, immunological, and environmental factors play a role. Nowadays, a higher proportion of elderly IBD patients with coexisting conditions, such as cardiovascular disease and/or diabetes is recorded, who require more complex treatment and became a great challenge for gastroenterologists. Furthermore, some patients do not respond to anti-IBD therapy. These facts, together with increasing comorbidities in patients with IBD, imply that urgent, more complex, novel therapeutic strategies in the treatment are needed. Glucagon-like peptides (GLPs) possess numerous functions in the human body such as lowering blood glucose level, controlling body weight, inhibiting gastric emptying, reducing food ingestion, increasing crypt cell proliferation, and improving intestinal growth and nutrient absorption. Thus, GLPs and dipeptidyl peptidase IV (DPP-IV) inhibitors have recently gained attention in IBD research. Several animal models showed that treatment with GLPs may lead to improvement of colitis. This review presents data on the multitude effects of GLPs in the inflammatory intestinal diseases and summarizes the current knowledge on GLPs, which have the potential to become a novel therapeutic option in IBD therapy.
\end{abstract}

Keywords Crohn's disease · GLP-1 · GLP-2 · Incretins · Inflammatory bowel disease · Ulcerative colitis

$\begin{array}{ll}\text { Abbreviations } \\ \text { CD } & \text { Crohn's disease } \\ \text { DPP-IV } & \text { Dipeptidyl peptidase IV } \\ \text { DSS } & \text { Dextran sulfate sodium } \\ \text { EEC } & \text { Enteroendocrine cells } \\ \text { GI } & \text { Gastrointestinal tract } \\ \text { GIP } & \text { Gastro-insulinotropic peptide } \\ \text { GLP } & \text { Glucagon-like peptide } \\ \text { GM-CSF } & \text { Granulocyte-macrophage } \\ & \text { colony-stimulating factor } \\ \text { IBD } & \text { Inflammatory bowel diseases } \\ \text { IFN- } \gamma & \text { Interferon } \gamma \\ \text { IGF-1 } & \text { Insulin-like growth factor 1 } \\ \text { IL } & \text { Interleukin } \\ \text { LPS } & \text { Lipopolysaccharide } \\ \text { PC 1/3 } & \text { Prohormone convertase 1/3 }\end{array}$

Jakub Fichna

jakub.fichna@umed.lodz.pl

1 Department of Biochemistry, Faculty of Medicine, Medical University of Lodz, Mazowiecka 6/8, 92-215 Lodz, Poland

$\begin{array}{ll}\text { PEG } & \text { Polyethylene glycosyl } \\ \text { SCFA } & \text { Short-chain fatty acids } \\ \text { TNBS } & 2,4,6 \text {-trinitrobenzenesulfonic acid } \\ \text { TNF- } \alpha & \text { Tumor necrosis factor } \alpha \\ \text { UC } & \text { Ulcerative colitis }\end{array}$

\section{Introduction}

Inflammatory bowel diseases (IBD), including Crohn's disease (CD) and ulcerative colitis (UC), are chronic, relapsing, intestinal inflammatory conditions with complex and yet unrevealed pathogenesis in which genetic, immunological, and environmental factors play a role (Sobczak et al. 2014). Inflammation in CD involves the entire gut wall and may occur in any part of gastrointestinal (GI) tract, whereas in UC, only colonic mucosa is affected (Zatorski et al. 2015). Both diseases are associated with alterations of the innate and adaptive immune system, microbiota, and epithelial function (Zietek et al. 2017; Siczek et al. 2017). Thus, inappropriate response to different pathogens in epithelial surface may cause release of inflammatory cytokines and induce inflammation. 
The incidence and prevalence of IBD are the highest in westernized countries, suggesting the increasing role of environmental factors (Molodecky et al. 2012). Importantly, while incidence of IBD is still rising, the mortality is low and thus the prevalence of IBD escalates globally (Molodecky et al. 2012). Nowadays, a higher proportion of elderly IBD patients with coexisting diseases, such as cardiovascular disease and/ or diabetes (Román and Muñoz 2011), is recorded; these patients require more complex treatment and became a great challenge for gastroenterologists. Moreover, recent studies showed that $15-40 \%$ of IBD patients suffer from obesity, which becomes an increasing problem in IBD treatment. It has also been evidenced that obese IBD patients have shorter time to first surgery as well as lower quality of life in comparison with non-obese IBD sufferers (Singh et al. 2017).

Currently, 5-aminosalicylates, immunosuppressive agents, corticosteroids, and biological therapeutics are widely used in IBD therapy. However, some patients do not respond to the treatment. Moreover, the side effects and economic costs of IBD patients' treatment cannot be ignored (Stallmach et al. 2010; van der Valk et al. 2016). These facts, together with increasing comorbidities in patients with IBD, imply that urgent, more complex, novel therapeutic strategies in the treatment are needed.

Enteroendocrine cells (EEC) comprise approximately $1 \%$ of the intestinal epithelium, but secrete more than 30 different peptide hormones, which makes them the largest endocrine system in the whole body (Worthington 2015). Most important bioactive compounds secreted by enteroendocrine $\mathrm{L}$ cells in the gut due to nutrient uptake are glucagon-like peptides (GLPs) including GLP-1 and GLP-2. GLP-1 plays a fundamental role in lowering blood glucose level and controlling body weight through stimulating the islet B cells to secrete insulin, inhibiting gastric emptying and reducing food ingestion (Zietek et al. 2017). Thus, GLP-1-based therapy is nowadays widely used in the treatment of type 2 diabetes, especially in obese subjects. On the other hand, GLP-2 analogs due to their effects on crypt cell proliferation, improving intestinal expansion and nutrient absorption, are used for intestinal injury and short bowel syndrome (Litvak et al. 1998; Yazbeck et al. 2010a). GLPs are rapidly degraded by dipeptidyl peptidase IV (DPP-IV), which results in their short half-lives in vivo. Thus, GLPs and DPP-IV inhibitors have recently gained attention in IBD research (Lund et al. 2011; Moran et al. 2013; Mimura et al. 2013; Duan et al. 2017; Salaga et al. 2018). Several investigations showed that treatment with GLPs may lead to improvement in dextran sulfate sodium (DSS)- and 2,4,6-trinitrobenzenesulfonic acid (TNBS)-induced colitis (Table 1).

This review presents data on the multitude effects of GLPs in the inflammatory intestinal diseases. It summarizes the current knowledge on GLPs, which have the potential to becoming a novel therapeutic option in IBD therapy.

\section{Glucagon-like peptides}

GLP-1 and GLP-2 derive from transcription product of the proglucagon gene gcg located on chromosome 2. Both GLP1 and GLP-2 are simultaneously produced via posttranslational processing of proglucagon by prohormone convertase $1 / 3$ (PC 1/3) (Fig. 1). GLP-1 is mainly produced in the ileum and the colon and it is known as the most potent incretin in the human body, which delays gastric emptying and lowers postprandial blood glucose level through augmentation of glucose-dependent insulin release (Lim et al. 2009). Moreover, GLP-1 is able to increase pancreatic B cell growth by promoting proliferation and reducing apoptosis (Ellingsgaard et al. 2011). The GLP-1 is released upon food consumption in a biphasic pattern with an early phase 10 $15 \mathrm{~min}$ and a longer second phase 30-60 min after meal. Secreted form of GLP-1 is GLP-1 (1-37), which is susceptible to amidation and proteolytic cleavage resulting in two equipotent biologically active forms GLP-1 (7-36) and GLP-1 (7-37). Endogenous GLP-1 is rapidly degraded by DPP-IV to inactive form GLP-1 (9-36), with half-life of approximately 2 min (Baggio and Drucker 2007). Meal ingestion, especially one rich in fats and carbohydrates, is the primary physiologic stimulus for GLP-1 secretion (Brubaker 2006). GLP-1 acts through a specific G protein-coupled receptor, which is expressed in pancreatic islets, the central nervous system, lungs, kidneys, heart, intestine, and immune cells, explaining the numerous roles for GLP-1 signaling beyond blood glucose control (Zietek and Rath 2016).

GLP-1, when secreted by L cells, may act in the endocrine (being released into the bloodstream) or paracrine fashion, i.e., stimulating neurons. GLP-1 exerts anorexigenic effect mediating signals from the gut to the brain through vagal nerves (Gallwitz 2012). Moreover, GLP-1 has a protective effect on neuronal damage as shown by reducing ibotenic acid-induced depletion of choline acetyltransferase immunoreactivity (Perry 2002). In addition, mice lacking GLP-1 receptor exhibit impairment of cognitive function, synaptic plasticity, and memory formation (Duan et al. 2017). Presented data show that GLP-1 possesses pleiotropic functions in multitude of diseases. To date, exenatide, liraglutide, albiglutide, lixisenatide, and dulaglutide, which are structurally modified GLP-1 analogs with extended half-life in vivo, are used in a clinical setting (Gupta et al. 2017).

GLP-2 is a 33-amino-acid proglucagon-derived peptide, which is expressed in the small intestine, mainly in terminal ileum. Moreover, expression of GLP-2 may be observed in the colon, although to a lesser extent than in the terminal ileum (Yusta et al. 2017). In the colon, the density of the GLP-2immunoreactive cells increases from proximal to distal part with maximal number of GLP-2-positive cells in the rectum (Litvak et al. 1998; Caddy et al. 2001; Schmidt et al. 2005). GLP-2 (133 ) is an active form of GLP-2 which is released in response to nutritional, hormonal, and neural stimulation. Recent data 
Table 1 GLPs analogs and DPP-IV inhibitors under investigation in preclinical studies

\begin{tabular}{|c|c|}
\hline Model & Treatment \\
\hline DSS-induced mouse model of colitis & $\begin{array}{l}\text { GLP-1 coated with sterically } \\
\text { stabilized phospholipid micelles } \\
\text { (GLP-1 SSM) } \\
15 \text { nmol/day i.p. }\end{array}$ \\
\hline $\begin{array}{l}\text { DSS-induced mouse model of colitis } \\
\text { Ischemia/reperfusion mouse model of } \\
\text { colitis }\end{array}$ & - \\
\hline $\begin{array}{l}\text { DSS-induced mouse model of colitis in } \\
\text { GLP-1R knockout mice }\end{array}$ & $\begin{array}{l}\text { GLP-1 agonist - Exendin }-4 \\
10 \mathrm{nmol} / \mathrm{kg} \text { s.c. }\end{array}$ \\
\hline
\end{tabular}

DSS-induced mouse model of colitis

GLP-2(2) degradation-resistant GLP-2 analog dimer

$200 \mu \mathrm{g} / \mathrm{kg} /$ day s.c.

GLP-2(2)

Radiation-induced mouse model of intestinal injury

DSS-induced mouse model of colitis

degradation-resistant GLP-2 analog dimer

$200 \mu \mathrm{g} / \mathrm{kg} /$ day s.c.

Teduglutide [Gly ${ }^{2}$ GLP-2

350 and 750 ng s.c.

DSS-induced mouse model of colitis

Teduglutide $\left[\mathrm{Gly}^{2}\right]$ GLP-2

$40 \mu \mathrm{g} / \mathrm{kg}$ s.c

\section{HLA-B27 rat model of colitis}

HLA-B27 rat model of colitis

TNF- $\alpha$ /actinomycin D-induced mouse model of intestinal injury

TNBS- and DSS-induced mouse model of colitis

IL-10 knockout (IL-10 $\frown$ ) mouse model of colitis

Indomethacin-induced rat model of enteritis

DSS-induced mouse model of colitis

DSS-induced rat model of colitis

DSS-induced model of colitis in DPP-IV deficient mouse

TNBS-induced mouse model of colitis DSS-induced mouse model of colitis

TNBS-induced mouse model of colitis DSS-induced mice model of colitis

DSS-induced mouse model of colitis
Teduglutide $\left[\mathrm{Gly}^{2}\right]$ GLP-2 $50 \mu \mathrm{g} / \mathrm{kg} /$ day i.v

Teduglutide $\left[\mathrm{Gly}^{2}\right]$ GLP-2

$50 \mu \mathrm{g} / \mathrm{kg} /$ day i.v or intraluminal pomp

Teduglutide $\left[\mathrm{Gly}^{2}\right]$ GLP-2

$200 \mu \mathrm{g} / \mathrm{kg}$ s.c.

GLP-2 (1-33)

$50 \mu \mathrm{g} / \mathrm{kg} / \mathrm{bid}$ s.c

GLP-2 (1-33)

$50 \mu \mathrm{g} / \mathrm{kg}$ twice daily s.c

\section{GLP2-2G-XTEN}

25 and $75 \mathrm{nmol} / \mathrm{kg}$ s.c.

GLP-2 analog peptide 10

$7.5 \mathrm{nmol} / \mathrm{kg}$ s.c. twice daily

PEGylated GLP-2

$12.5,25$ and $100 \mathrm{nmol} / \mathrm{kg}$ i.p.

\section{$-$}

DPP-IV inhibitor - EMDB-1

$1 \mathrm{mg} / \mathrm{kg}$ i.c.

\section{DPP-IV inhibitor}

Tyr-Pro-D-Ala- $\mathrm{NH}_{2}$

1 and $3 \mathrm{mg} / \mathrm{kg}$ i.c.

DPP-IV inhibitor - ER-319711

$100 \mathrm{mg} / \mathrm{kg}$ p.o. responses, decrease in structural damage of the
Result

Improvement of intestinal, epithelial architecture alleviation of diarrhea, increase in goblet cell number, reduction of IL- $1 \beta$ expression

Plasma GLP-1 levels were increased after LPS administration through TLR-4 dependent manner prior to measurable changes in inflammatory status and plasma cytokine.

GLP-1R knockout mice exhibited dysregulated intestinal gene expression, an abnormal representation of microbial species in feces and enhanced sensitivity to intestinal injury after DSS administration. Exendin-4 administration resulted in increased expression of genes encoding cytokines and chemokines in injured intestine

Reference

Anbazhagan et al. 2017

Lebrun et al. 2017

Yusta et al. 2015

Gu et al. 2018

$$
\text { crypt depth and crypt cell proliferation }
$$

Protection against radiation-induced gastrointestinal toxicity, down-regulation of inflammatory intestine and apoptosis of intestinal cells

Increase in total body weight, colon length, crypt depth and integrity of the colon, reduction in IL-1 $\beta$ expression

Increase in overall survival, intestinal weight, number of proliferating cells in colonic crypts, decrease in body weight loss and colonic damage

Decrease in histological lesions in small and large intestine, decrease in expression of IFN- $\gamma$ and $\mathrm{TNF}-\alpha$

Improvements of stool consistency and histological inflammation scores

Induction of epithelial cell proliferation, inhibition of apoptosis, prevention of intestinal damage and oxidative stress

Increase in crypt depth, villus height, Significant reduction of proinflammatory markers such as IL- $1 \beta$, INF- $\gamma$ and TNF- $\alpha$

Increase in IGF-1 production, Decrease in animal weight loss, MPO levels, crypt proliferation crypt cell apoptosis, proinflammatory cytokines, CD4 (+) T cell population

Increase in small intestine weight and length, reduction in inflammatory scores and proinflammatory cytokines levels

Increase in small intestine weight and length, Reduction in inflammatory cytokine levels

Reduction of colon damage scores, proinflammatory cytokine expression and increase in body weight

Lack of DPP-IV resulted in increase of myeloperoxidase activity and expression of NF-KB p65 subunit

Increase in total body weight, colon length and weight, Reduction of colon damage scores, myeloperoxidase activity, bowel thickness, IL-1 $\beta$ and TNF- $\alpha$ expression

Reduction of macroscopic and microscopic colon damage scores, inflammatory cytokines and myeloperoxidase activity

Amelioration of disease activity index and colon length and increase in crypt height
Gu et al. 2017

L'Heureux 2003

Alavi et al. 2000

Arthur et al. 2004

Arda-Pirincci and Bolkent 2011

Sigalet et al. 2007

Ivory et al. 2008

Alters et al. 2012

Yang et al. 2018

Qi et al. 2017

Detel et al. 2016

Salaga et al. 2017

Salaga et al. 2018

Ban et al. 2011
Drucker et al. 1999

$D P P-I V$, dipeptidyl peptidase IV; $D S S$, dextran sulfate sodium; $G L P$, glucagone-like peptide; i.c., intracolonic; i.p., intraperitoneal; $I G F$, insulin growth factor; $I N F-\gamma$, interferon $\gamma$; LPS, lipopolysaccharide; $M P O$, myeloperoxidase; p.o., per os; s.c., subcutaneous; TNBS, 2,3,6, -Trinitrobenzenesulfonic acid; $T N F \alpha$, tumor necrosis factor $\alpha$ 


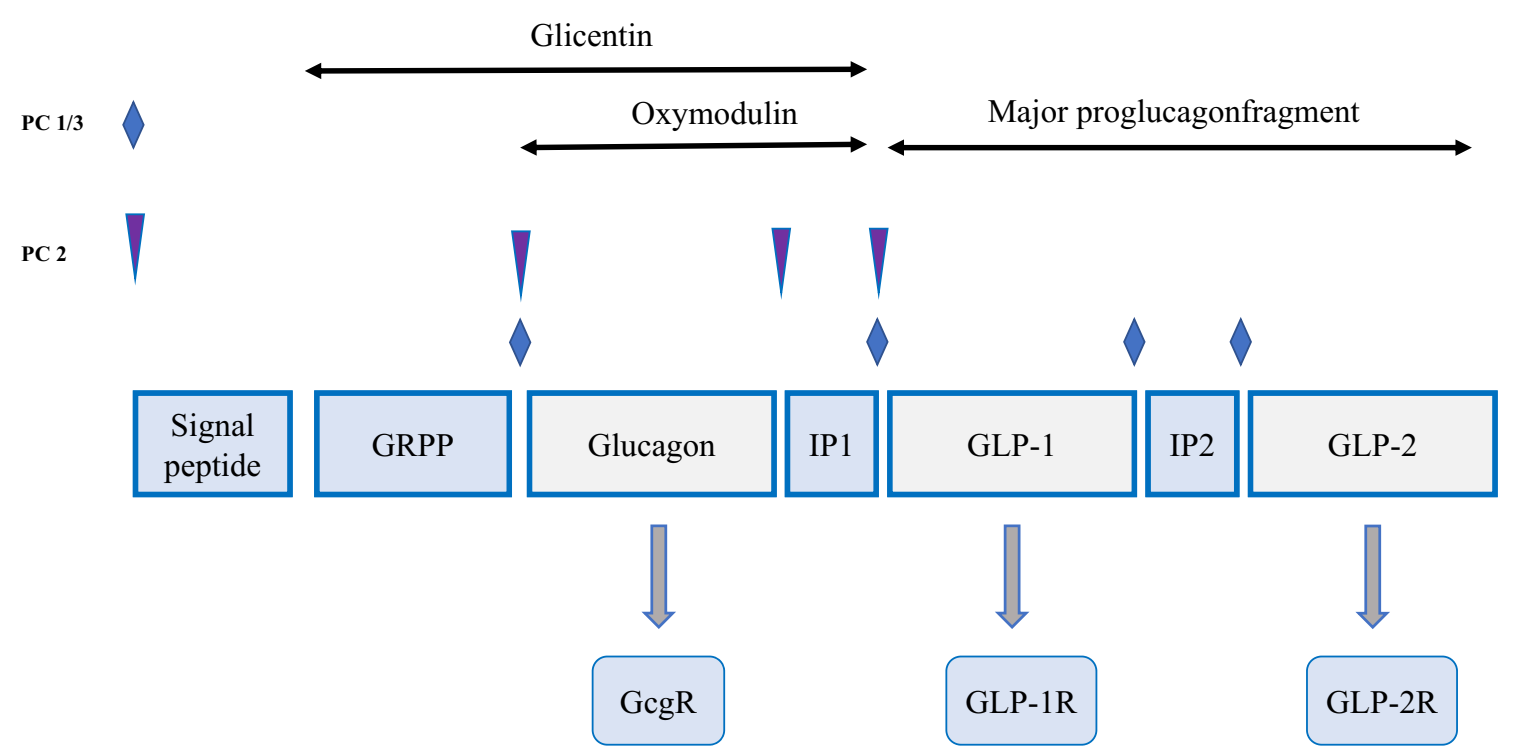

Fig. 1 Production of GLPs in humans from $g c g$ gene. IP1, inverting peptide 1; IP2, inverting peptide 2; GcgR, glucagon receptor; GLP-1, glucagon-like peptide 1; GLP-2. glucagon-like peptide 2; GLP-1R.

glucagon-like peptide 1 receptor; GLP-2R, glucagon-like peptide 2 receptor; GRPP. glicentin-related pancreatic polypeptide, PC 1/3, prohormone convertase $1 / 3$

demonstrated that dietary fiber and short-chain fatty acids (SCFA), carbohydrates, and fats are potent stimulators of GLP2 secretion. The GLP-2 (3-33), a biologically inactive form of GLP-2, which is a product of degradation of N-terminus of GLP2 (1-33) by DPP-IV, may act as a weak partial agonist of the GLP-2 receptor in a negative feedback mechanism.

GLP-2 acts through a G protein-coupled receptor GLP-2R. Current research shows that stimulation through GLP-2/GLP-2R signaling involves activation of adenylyl cyclase, increased cAMP and PKA accumulation, and eventually ELK-1/c-fos/cjun gene activation. Moreover, data show that MAP, EGFR/TyrK pathways are involved (Martin et al. 2006). It is also known as a GI growth factor: it increases intestinal blood flow (Mayo et al. 2017), increases absorption (Feng et al. 2017), proliferation, decreases apoptosis ( $\mathrm{Li}$ et al. 2016) and reduces intestinal permeability (Zhang et al. 2018), and suppresses gastric secretion and motility. Recent data demonstrated that exogenous administration of GLP-2 correlates with increase in total gut weight, length, villus height, crypt depth, and crypt cell proliferation (Gu et al. 2018). GLP-2 and its analogs showed to be efficient in the treatment of short bowel syndrome in children and adults as demonstrated by increase in nutrient absorption, reduction in parenteral nutrition requirements, and improved $\mathrm{Z}$ scores in pediatric population (Sigalet 2018).

\section{DPP-IV, a major enzyme responsible for GLPs degradation}

DPP-IV is a type II integral transmembrane glycoprotein. In plasma, a soluble form of DPP-IV with preserved catalytic activity can be detected (Zhong et al. 2013, 2015). Although

the exact mechanism of DPP-IV expression regulation remains poorly understood, TNF- $\alpha$ has been implicated as one of the regulators (Duan et al. 2017). As primary substrates for DPP-IV are GLP-1, GLP-2, and gastro-insulinotropic peptide (GIP), DPP-IV gene-deficient mice show improved postprandial glucose control and are resistant to progression of obesity and hyperinsulinemia (Drucker 2002; Gupta et al. 2017). Inhibition of DPP-IV activity in wild-type mice by pharmacological agents results in improvement in glucose tolerance, whereas this effect has not been observed in DPP-IV knockout mice (Marguet et al. 2000). Besides GLPs, DPP-IV is able to cleave some chemokines and cytokines such as IL-3, and granulocyte-macrophage colony-stimulating factor (GMCSF), thereby regulating the immune responses (Kameoka et al. 1993; Broxmeyer et al. 2012). DPP-IV also exhibits non-catalytic actions through interaction with caveolin-1, fibronectin, and adenosine deaminase. Interaction of DPP-IV with the latter may result in the promotion of $\mathrm{T}$ cell activation (Kameoka et al. 1993; Broxmeyer et al. 2012). A recent study performed by Higashijima et al. demonstrated that DPP-IV inhibitors alter immune cell recruitment and reduce macrophage infiltration probably through GLP-1-dependent signaling in a rat model of nephritis (Higashijima et al. 2015).

DPP-IV is also responsible for the regulation of macrophage/dendric cell-mediated adipose tissue inflammation (Zhong et al. 2013). In addition, in non-obese diabetic mice, DPP-IV inhibitors significantly increase Treg expansion and TGF- $\beta$ level. DPP-IV activity is significantly increased in obese subjects and in animal models of obesity (Yang et al. 2007; Lee et al. 2013).

Furthermore, DPP-IV inhibition prevented inflammation and mediated neuroprotective effect in two major complications of 
diabetes mellitus, namely ischemic stroke and retina damage. This effect was attributed to antioxidant properties of DPP-IV, suppression of NF- $\mathrm{BB}, \mathrm{IL}-6$, TNF- $\alpha$, and elevation of IL-10 (Gonçalves et al. 2014; El-Sahar et al. 2015).

\section{Role of GLP-1 in inflammatory regulation in IBD}

To date, researchers focused mainly on the anti-diabetic and anti-atherosclerotic effects of GLP-1 agonists, while the GI effects remained poorly understood. Nevertheless, a study by Jensen et al. (2018) showed that patients after colectomy exhibit increased risk of type 2 diabetes when compared with non-colectomy patients (HR 1.40; 95\% confidence interval $\mathrm{Cl}$ 1.21 to 1.62 ). In another study, Palnaes et al. showed that release of GLP-1 in response to the intake of glucose is slower in UC patients who underwent colectomy (Palnaes Hansen et al. 1997). Moreover, postprandial GLP-1 response was also impaired in patients with ileostomy (Robertson et al. 1999). These data reveal the connection between GLP-1 and the colon; however, it is still not known whether inflammation also affects the GLP-1 release in IBD. Interestingly, subsequent studies showed that GLP-1R mRNA was reduced in samples obtained from inflamed area of the colon in IBD patients (Bang-Berthelsen et al. 2016). In contrast, GLP-1 was upregulated in IBD patients' serum, when compared with controls (Keller et al. 2009, 2015). These data clearly show that GLP-1 expression may be associated with inflammation in IBD.

To explore how GLP-1 is implicated in IBD studies were performed in experimental animal models of colitis. Yusta et al. demonstrated that GLP-1R knockout mice exhibited dysregulated intestinal gene expression such as IL-1 $\beta$ IL-6, IL-12 $\beta$, and trefoil factors 1 and 2. Moreover, GLP-1R knockout mice exhibited abnormal representation of microbial species in feces as well as enhanced sensitivity to intestinal injury after DSS administration in comparison to wild-type mice. Moreover, the authors showed that bone marrow transplant using wild-type mice donors normalized expression of multiple genes regulating immune function and epithelial integrity. Moreover, administration of Exendin-4, a GLP-1 agonist, resulted in induction of expression of genes encoding multiple cytokines and chemokines responsible for immune response (Yusta et al. 2015). In T cell adoptive transferinduced colitis, the GLP-1 expression in colonic tissue was significantly lower in mice with colitis when compared with control mice (Schmidt et al. 2000). Moreover, increased level of GLP-1 was detected in mice with colitis after DPP-IV inhibitor treatment when compared with untreated mice (Yazbeck et al. 2010b). In a study performed by BangBerthelsen et al. (2016), treatment with GLP-1 analog liraglutide significantly improved histological scores, colon weight/length ratio, and reduced inflammatory cytokines and chemokines such as CCL20, IL-33, and IL-22. Treatment with GLP-1 coated with sterically stabilized phospholipid micelles (GLP-1-SSM) for 7 consecutive days in a dose $15 \mathrm{nmol} /$ day markedly alleviated the development of DSS-induced colitis in mice by significantly improving epithelial architecture and reducing the expression of proinflammatory cytokines such as IL-1 $\beta$ (Anbazhagan et al. 2017). Lebrun et al. evaluated the role of GLP-1 in mucosal integrity and inflammation. They demonstrated that plasma GLP-1 level is increased by lipopolysaccharide (LPS) administration in mice, in DSS-induced and ischemia/reperfusion-induced colitis model, through tolllike receptor 4-dependent mechanism. Importantly, the authors showed that GLP-1 may be considered a sensor of local inflammation and barrier integrity (Lebrun et al. 2017).

\section{Role of GLP-2 in inflammatory regulation in IBD}

Administration of teduglutide, a GLP-2 analog to mice with DSS-induced colitis, resulted in a significantly greater small bowel and colon weight and length compared with untreated mice. Moreover, mice treated with teduglutide had improvements in histological morphology and crypt cell proliferation (Drucker et al. 1999). In addition, teduglutide was as effective as sulfasalazine and corticosteroids (L'Heureux 2003). In the HLA-B27 rat model of colitis, administration of teduglutide at the dose of $50 \mu \mathrm{g} / \mathrm{kg} /$ day decreased histological lesions in small and large intestine, decreased expression of the inflammatory cytokines, such as IFN- $\gamma$ and TNF- $\alpha$, and improved stool consistency in comparison with control group (Alavi et al. 2000; Arthur et al. 2004). In another study performed by Sigalet et al., therapeutic effect of GLP-2 administration in TNBS- and DSS-induced mouse model of colitis was investigated. GLP-2 injection resulted in increase in crypt depth and villus height as well as significant reduction of proinflammatory markers such as IL- $1 \beta$, IFN- $\gamma$, and TNF- $\alpha$ (Sigalet et al. 2007). In the IL-10 knockout mouse model of colitis, administration of GLP-2 in dose $50 \mu \mathrm{g} / \mathrm{kg}$ s.c. for 5 consecutive days resulted in a significant amelioration of animal weight loss, reduction of histopathological inflammation score, and myeloperoxidase levels compared with control mice. In addition, GLP-2 treatment reduced crypt proliferation and apoptosis, decreased proinflammatory cytokines (IL-1 $\beta$, IFN- $\gamma$, and TNF- $\alpha$ ) levels, and increased the level of IL-4. Moreover, GLP-2 injection reduced CD4(+) T cell population. Researchers suggested that the anti-inflammatory effects of GLP-2 are IL-10-independent and that GLP-2 alters the mucosal response to inflammation through a decrease of lamina propria macrophage TNF- $\alpha$ as well as an increase in insulinlike growth factor 1 (IGF-1) production (Ivory et al. 2008). In another study, Arda-Pirincci et al. demonstrated that teduglutide has a protective, antiapoptotic, proliferative, and 
antioxidant effects in TNF- $\alpha$ /actinomycin D-induced intestinal injury (Arda-Pirincci and Bolkent 2011).

Considering short half-life of native GLP-2 in human circulation and promising results of teduglutide, which half-life is modestly extended to $3-5 \mathrm{~h}$, current research focuses on an increase of the time of GLP-2 action by developing new, more stable, GLP-2 analogs. Yang et al. (2018) investigated a GLP-2 analog, peptide-10, with 10 times longer life. Peptide-10 exhibited improved efficiency and better intestinotrophic effects in comparison with teduglutide in DSS-induced mouse model of colitis (Yang et al. 2018). Alters et al. reported that GLP-2 analog GLP$2 \mathrm{G}$ genetically fused to protein polymers called XTEN has a greatly improved half-life $(240 \mathrm{~h})$ and lower dose requirements in a rat model of indomethacin-induced inflammation. According to presented data, one injection of GLP-2$2 \mathrm{G}-\mathrm{XTEN}$ in a dose of $75 \mathrm{nmol} / \mathrm{kg}$ is as effective as 10 injections of GLP-2G in a dose of $12.5 \mathrm{nmol} / \mathrm{kg}$. Administration of GLP-2-2G-XTEN resulted in a significant increase in small intestine weight and length as well as reduced inflammation scores and proinflammatory cytokines (Alters et al. 2012). In another study, Qi et al. investigated the effect of polyethylene glycosylated (PEGylted) porcine GLP-2, with a half-life 16-fold longer than native GLP-2, in the DSS-induced rat model of colitis. PEG-GLP2 reduced colon damage scores, and increased body weight and proinflammatory cytokines expression (Qi et al. 2017). $\mathrm{Gu}$ et al. designed degradation-resistant GLP-2 analog dimer, GLP-2(2), which increased total gut weight, length, and villus height as well as crypt depth and crypt cell proliferation in DSS-induced mouse model of colitis $(\mathrm{Gu}$ et al. 2018). Moreover, administration of GLP-2(2) in a radiation-induced mouse model of intestine injury protected against radiation-induced GI toxicity and resulted in downregulation of inflammatory responses, decrease in structural damage of the intestine, and apoptosis of intestinal cells (Gu et al. 2017).

Xiao et al. reported that UC and CD patients with active disease have elevated levels of bioactive GLP-2 compared with healthy subjects (Xiao et al. 2000). In contrast, a study performed by Schmidt et al. demonstrated no difference in either plasma or tissue concentrations of meal stimulated GLP-2 between patients with IBD and non-IBD controls (Schmidt et al. 2005). Teduglutide in three different doses, $0.05,0.1$, and $0.2 \mathrm{mg} / \mathrm{kg}$ daily, has been investigated in a prospective placebo-controlled study in 100 human subjects for the treatment of moderate to severe $\mathrm{CD}$ in an 8-week trial. It was demonstrated that remission was induced in over 55\% of study participants at the highest dose, compared with only $33 \%$ of those receiving placebo after 8 weeks, although study failed to reach statistical significance over placebo (Buchman et al. 2010). To our knowledge, no other clinical trials with IBD patients were performed.

\section{Inhibition of DPP-IV as a potential therapeutic strategy in IBD}

The involvement of DPP-IV in the pathogenesis of IBD might be dependent on two major pathways: the catalytic and noncatalytic (Duan et al. 2017). It has been proposed that the protective effect of DPP-IV inhibition may be a result of increased levels of GLP-1 and GLP-2 (Yazbeck et al. 2010b; Ban et al. 2011). Detel et al. investigated the role of DPP-IV in the pathogenesis of colitis (Detel et al. 2016). In DPP-IVdeficient mice induction of colitis by DSS resulted in a stronger increase of myeloperoxidase activity and expression of NF-B p65 subunit in the colonic tissue compared with wildtype mice (Detel et al. 2016). Furthermore, in DPP-IV deficient mice, increase in the percentage of splenic CD+ cells and NKT cells as well as increase in macrophages was observed (Detel et al. 2016). Salaga et al. (2017) demonstrated that EMDB-1, a new peptide analog of endomorphin-2, with a potential to inhibit DPP-IV ameliorated colonic inflammation in both DSS- and TNBS-induced mouse model of colitis. Moreover, treatment with EMDB-1 extended half-life of GLP-2 (Salaga et al. 2017). In another study, Salaga et al. (2018) evaluated the series of novel EMDB-1 analogs and evaluated their inhibitory potential. Authors demonstrated that the novel peptide inhibitor of DPP-IV (Tyr-Pro-D-Ala-NH $\mathrm{N}_{2}$ ) blocks DPP-IV activity and attenuates acute, semi-chronic, and relapsing TNBS- and DSS-induced colitis in mice after topical administration (Salaga et al. 2018).

On the other hand, DPP-IV is responsible for the degradation of numerous signaling molecules such as endogenous opioid peptides including endorphins, dynorphins, and enkephalins which play crucial role in basic functions of the GI tract (e.g., motility, pain signaling, and secretion) (Sałaga et al. 2013). Thus, it cannot be excluded that in some IBD patients' disruption of GI tract homeostasis may be observed leading to development or exacerbation of IBD. Thus, there is an unmet need for research on the mechanism of DPP-IV inhibitors actions in the GI tract as well as long-term postmarketing surveillance of these drugs to assess their safety.

Concurrently, the results of a meta-analysis performed by Radel et al. (2019) who investigated the risk of developing IBD in patients on DPP-IV inhibitor therapy point out the need for further research. In this meta-analysis, which included 16 studies and 198,404 patients, the authors demonstratedusing primary random-effects analysis - that the DPP-IV inhibitor exposure resulted in a non-significant increase of IBD risk $(\mathrm{RR}=1.52,95 \% \mathrm{Cl}=0.72-3.23)$. However, based on conservative random-effect analysis, DPP-IV inhibitors did not appear to increase the risk of developing IBD. This means that there is an urgent need to develop prospective studies unraveling the exact impact of DPP-IV administration on IBD. The main disadvantage of the cited meta-analysis is that all findings were driven by the inclusion of 1 large study 
evaluating the effect of DPP-IV inhibitors on IBD risk in 141,170 individuals whereas other 15 studies accounted for 57,234 individuals (Abrahami et al. 2018; Radel et al. 2019). Of note, the effect of DPP-IV in conditions such as IBD is not well understood. On the contrary, studies in animal models of IBD suggest that the use of DPP-IV inhibitors decreases disease activity. On the other hand, IBD patients have lower serum DPPIV concentrations in comparison with healthy subjects; however, DPP-IV expression on T cells from IBD patients is elevated. Furthermore, lower concentrations of DPP-IV are inversely associated with increased disease activity, although is not clear whether this is the cause or consequence of disease.

\section{Future perspectives}

Currently, there is not enough data from randomized placebocontrolled trials in patients with IBD to determine the efficiency of GLPs in this disease. Considering promising preclinical data (Table 1) and clinical pilot study results in the GLP-2 analog, teduglutide may have potential to become a new therapeutic option in IBD treatment, showing higher response and remission rates in comparison to placebo (Buchman et al. 2010). On the other hand, it is worrisome that up to $42 \%$ of patients who were treated with GLP-2 analog in induction phase discontinued the study (Buchman et al. 2010).
Nevertheless, further studies are needed to determine the safety, tolerability, and clinical effectiveness of GLPs analogs in therapy. Moreover, new studies should be developed to assess the effect of GLP-2, as well as GLP-1 analogs and DPP-IV inhibitors on intestinal mucosal healing. Considering the fact that teduglutide targets barrier function of the gut and available IBD therapies target mainly immune and inflammatory pathways, new studies should focus on determination whether administration of teduglutide would allow to decrease a dose of corticosteroids or biologics in IBD patients (Blonski et al. 2013). Of note, development of new compounds with longer half-life and higher stability will decrease the number of injections and certainly improve patients' acceptance of treatment.

\section{Conclusions}

Apart from typical symptoms due to extensive intestinal inflammation, patients with IBD also suffer from malnutrition and metabolic disorders. Both GLP-1 and GLP-2 exert potential anti-inflammatory properties as well as improve glycemic control, nutrient absorption, and stimulate intestinal proliferation. Taking into consideration all currently available data, GLP-2 might be much more promising than GLP-1. Nevertheless, more studies emerge on the role of GLP-1 in

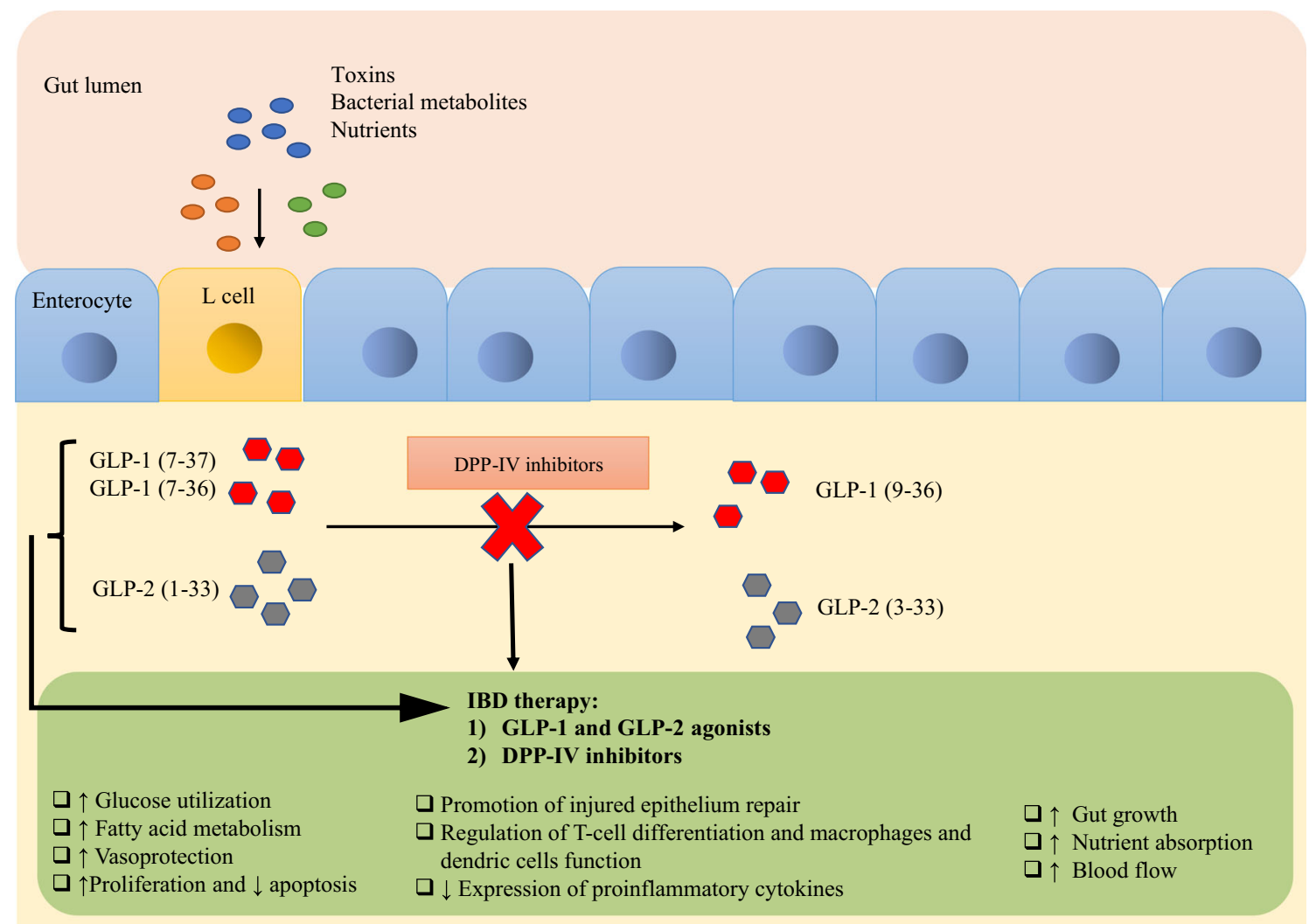

Fig. 2 GLPs as novel therapeutic options in IBD — potential mechanisms of action 
mucosal integrity and modulation of inflammatory response and suggest that it may become an equally important tool in the IBD therapy. It may thus be suggested that targeting both GLPs will be the most beneficial treatment for IBD sufferers, especially in obese patients not only decreasing inflammation but also helping maintain proper weight. The potential mechanism of GLPs action in IBD may include promotion of tissue repair of injured epithelium, regulation of $\mathrm{T}$ cell differentiation and functions, regulation of innate immune cells such as macrophages and dendric cells, and reduction of proinflammatory cytokines (Fig. 2). Whereas corticosteroids and biologics affect immune system and may expose patients to adverse effects such as infections, GLPs do not act directly as immunosuppressants and may become first-line therapy in the treatment of IBD. Nevertheless, future clinical randomized trial is warranted to determine the effectiveness of currently used therapies.

Author contributions HZ, MS, and JF provided the overall concept and framework of the manuscript; HZ researched and identified appropriate articles, and wrote the manuscript; HZ, MS, and JF revised the manuscript; all authors approved the final version of the manuscript.

Funding information Financial support: Supported by the Medical University of Lodz (502-03/1-156-04/502-14-339 to HZ and 503/1156-04/503-11-001 to JF).

Hubert Zatorski is the recipient of Diamentowy Grant Program of the Polish Ministry of Science and Higher Education (No. 0202/DIA/2015/44).

Hubert Zatorski is the recipient of the scholarship sponsored by the Polpharma Scientific Foundation.

\section{Compliance with ethical standards}

Conflict of interest The authors declare that they have no conflict of interest.

Open Access This article is distributed under the terms of the Creative Commons Attribution 4.0 International License (http:// creativecommons.org/licenses/by/4.0/), which permits unrestricted use, distribution, and reproduction in any medium, provided you give appropriate credit to the original author(s) and the source, provide a link to the Creative Commons license, and indicate if changes were made.

\section{References}

Abrahami D, Douros A, Yin H, et al (2018) Dipeptidyl peptidase-4 inhibitors and incidence of inflammatory bowel disease among patients with type 2 diabetes: population based cohort study. BMJ 360:k872. https://doi.org/10.1136/bmj.k872

Alavi K, Schwartz MZ, Palazzo JP, Prasad R (2000) Treatment of inflammatory bowel disease in a rodent model with the intestinal growth factor glucagon-like peptide-2. J Pediatr Surg 35:847-851. https:// doi.org/10.1053/jpsu.2000.6861

Alters SE, McLaughlin B, Spink B, Lachinyan T, Wang CW, Podust V, Schellenberger V, Stemmer WPC (2012) GLP2-2G-XTEN: a pharmaceutical protein with improved serum half-life and efficacy in a rat Crohn's disease model. PLoS One 7:e50630. https://doi.org/10. 1371/journal.pone.0050630

Anbazhagan AN, Thaqi M, Priyamvada S, Jayawardena D, Kumar A, Gujral T, Chatterjee I, Mugarza E, Saksena S, Onyuksel H, Dudeja PK (2017) GLP-1 nanomedicine alleviates gut inflammation. Nanomed Nanotechnol Biol Med 13:659-665. https://doi.org/10. 1016/j.nano.2016.08.004

Arda-Pirincci P, Bolkent S (2011) The role of glucagon-like peptide-2 on apoptosis, cell proliferation, and oxidant-antioxidant system at a mouse model of intestinal injury induced by tumor necrosis factoralpha/actinomycin D. Mol Cell Biochem 350:13-27. https://doi.org/ 10.1007/s11010-010-0678-0

Arthur GL, Schwartz MZ, Kuenzler KA, Birbe R (2004) Glucagonlike peptide-2 analogue: a possible new approach in the management of inflammatory bowel disease. J Pediatr Surg 39:448-452 discussion $448-52$

Baggio LL, Drucker DJ (2007) Biology of incretins: GLP-1 and GIP. Gastroenterology 132:2131-2157. https://doi.org/10.1053/j.gastro. 2007.03.054

Ban H, Bamba S, Imaeda H et al (2011) The DPP-IV inhibitor ER319711 has a proliferative effect on the colonic epithelium and a minimal effect in the amelioration of colitis. Oncol Rep 25:16991703. https://doi.org/10.3892/or.2011.1223

Bang-Berthelsen CH, Holm TL, Pyke C, Simonsen L, Søkilde R, Pociot F, Heller RS, Folkersen L, Kvist PH, Jackerott M, Fleckner J, Vilién M, Knudsen LB, Heding A, Frederiksen KS (2016) GLP-1 induces barrier protective expression in Brunner's glands and regulates colonic inflammation. Inflamm Bowel Dis 22:2078-2097. https://doi. org/10.1097/MIB.0000000000000847

Blonski W, Buchner AM, Aberra F, Lichtenstein G (2013) Teduglutide in Crohn's disease. Expert Opin Biol Ther 13:1207-1214. https://doi. org/10.1517/14712598.2013.815721

Broxmeyer HE, Hoggatt J, O'leary HA et al (2012) Dipeptidylpeptidase 4 negatively regulates colony-stimulating factor activity and stress hematopoiesis. Nat Med 18:1786-1796. https://doi.org/10.1038/ nm.2991

Brubaker PL (2006) The glucagon-like peptides: pleiotropic regulators of nutrient homeostasis. In: Annals of the New York Academy of Sciences. pp 10-26

Buchman AL, Katz S, Fang JC, Bernstein CN, Abou-Assi SG (2010) Teduglutide, a novel mucosally active analog of glucagon-like peptide-2 (GLP-2) for the treatment of moderate to severe Crohn's disease. Inflamm Bowel Dis 16:962-973. https://doi.org/10.1002/ibd. 21117

Caddy GR, Johnston CF, Ardill JES, Pogue KM, Collins JSA, Gardiner KR, Watson PR (2001) Distribution of glucagon-like peptide-2 (GLP-2) in normal colonic tissue. Gastroenterology 120:A683. https://doi.org/10.1016/S0016-5085(08)83400-2

Detel D, Buljevic S, Pucar LB, Kucic N, Pugel EP, Varljen J (2016) Influence of CD26/dipeptidyl peptidase IV deficiency on immunophenotypic changes during colitis development and resolution. J Physiol Biochem 72:405-419. https://doi.org/10.1007/ s13105-016-0491-7

Drucker DJ (2002) Biological actions and therapeutic potential of the glucagon-like peptides. Gastroenterology 122:531-544

Drucker DJ, Yusta B, Boushey RP et al (1999) Human [Gly2]GLP-2 reduces the severity of colonic injury in a murine model of experimental colitis. Am J Phys 276:G79-G91

Duan L, Rao X, Braunstein Z, Toomey AC, Zhong J (2017) Role of incretin axis in inflammatory bowel disease. Front Immunol 8:1734

Ellingsgaard H, Hauselmann I, Schuler B, Habib AM, Baggio LL, Meier DT, Eppler E, Bouzakri K, Wueest S, Muller YD, Hansen AMK, Reinecke M, Konrad D, Gassmann M, Reimann F, Halban PA, Gromada J, Drucker DJ, Gribble FM, Ehses JA, Donath MY (2011) Interleukin-6 enhances insulin secretion by increasing 
glucagon-like peptide-1 secretion from $\mathrm{L}$ cells and alpha cells. Nat Med 17:1481-1489. https://doi.org/10.1038/nm.2513

El-Sahar AE, Safar MM, Zaki HF et al (2015) Sitagliptin attenuates transient cerebral ischemia/reperfusion injury in diabetic rats: implication of the oxidative-inflammatory-apoptotic pathway. Life Sci 126:81-86. https://doi.org/10.1016/j.lfs.2015.01.030

Feng Y, Demehri FR, Xiao W, Tsai YH, Jones JC, Brindley CD, Threadgill DW, Holst JJ, Hartmann B, Barrett TA, Teitelbaum DH, Dempsey PJ (2017) Interdependency of EGF and GLP-2 signaling in attenuating mucosal atrophy in a mouse model of parenteral nutrition. CMGH 3:447-468. https://doi.org/10.1016/j.jcmgh. 2016.12.005

Gallwitz B (2012) Anorexigenic effects of GLP-1 and its analogues. Handb Exp Pharmacol 209:185-207. https://doi.org/10.1007/9783-642-24716-3 8

Gonçalves A, Marques C, Leal E, Ribeiro CF, Reis F, Ambrósio AF, Fernandes R (2014) Dipeptidyl peptidase-IV inhibition prevents blood-retinal barrier breakdown, inflammation and neuronal cell death in the retina of type 1 diabetic rats. Biochim Biophys Acta Mol Basis Dis 1842:1454-1463. https://doi.org/10.1016/j.bbadis. 2014.04.013

Gu J, Liu S, Mu N, Huang T, Zhang W, Zhao H, Shu Z, Zhang C, Hao Q, Li W, Xue X, Zhang W, Zhang Y (2017) A DPP-IV-resistant glucagon-like peptide-2 dimer with enhanced activity against radiation-induced intestinal injury. J Control Release 260:32-45. https://doi.org/10.1016/j.jconrel.2017.05.020

Gu J, Liu J, Huang T, Zhang W, Jia B, Mu N, Zhang K, Hao Q, Li W, Liu W, Zhang W, Zhang Y, Xue X, Zhang C, Li M (2018) The protective and anti-inflammatory effects of a modified glucagon-like peptide-2 dimer in inflammatory bowel disease. Biochem Pharmacol 155: 425-433. https://doi.org/10.1016/j.bcp.2018.07.027

Gupta A, Jelinek HF, Al-Aubaidy H (2017) Glucagon like peptide-1 and its receptor agonists: their roles in management of type 2 diabetes mellitus. Diabetes Metab Syndr Clin Res Rev 11:225-230

Higashijima Y, Tanaka T, Yamaguchi J, Tanaka S, Nangaku M (2015) Anti-inflammatory role of DPP-4 inhibitors in a nondiabetic model of glomerular injury. Am J Physiol Physiol 308:F878-F887. https:// doi.org/10.1152/ajprenal.00590.2014

Ivory CPA, Wallace LE, McCafferty D-M, Sigalet DL (2008) Interleukin10-independent anti-inflammatory actions of glucagon-like peptide 2. AJP Gastrointest Liver Physiol 295:G1202-G1210. https://doi. org/10.1152/ajpgi.90494.2008

Jensen AB, Sørensen TI, Pedersen O et al (2018) Increase in clinically recorded type 2 diabetes after colectomy. Elife 7. https://doi.org/10. 7554/eLife.37420

Kameoka J, Tanaka T, Nojima Y, Schlossman S, Morimoto C (1993) Direct association of adenosine deaminase with a $\mathrm{T}$ cell activation antigen, CD26. Science 261:466-469

Keller J, Beglinger C, Holst JJ, Andresen V, Layer P (2009) Mechanisms of gastric emptying disturbances in chronic and acute inflammation of the distal gastrointestinal tract. Am J Physiol Liver Physiol 297: G861-G868. https://doi.org/10.1152/ajpgi.00145.2009

Keller J, Binnewies U, Rösch M, Juul Holst J, Beglinger C, Andresen V, Layer P (2015) Gastric emptying and disease activity in inflammatory bowel disease. Eur J Clin Investig 45:1234-1242. https://doi. org/10.1111/eci.12542

L'Heureux M-C (2003) Glucagon-like peptide-2 and common therapeutics in a murine model of ulcerative colitis. J Pharmacol Exp Ther 306:347-354. https://doi.org/10.1124/jpet.103.051771

Lebrun LJ, Lenaerts K, Kiers D, Pais de Barros JP, le Guern N, Plesnik J, Thomas C, Bourgeois T, Dejong CHC, Kox M, Hundscheid IHR, Khan NA, Mandard S, Deckert V, Pickkers P, Drucker DJ, Lagrost L, Grober J (2017) Enteroendocrine L cells sense LPS after gut barrier injury to enhance GLP-1 secretion. Cell Rep 21:1160 1168. https://doi.org/10.1016/j.celrep.2017.10.008
Lee SA, Kim YR, Yang EJ, Kwon EJ, Kim SH, Kang SH, Park DB, Oh BC, Kim J, Heo ST, Koh G, Lee DH (2013) CD26/DPP4 levels in peripheral blood and T cells in patients with type 2 diabetes mellitus. J Clin Endocrinol Metab 98:2553-2561. https://doi.org/10.1210/jc. 2012-4288

Li N, Liu BW, Ren WZ, Liu JX, Li SN, Fu SP, Zeng YL, Xu SY, Yan X, Gao YJ, Liu DF, Wang W (2016) GLP-2 attenuates LPS-induced inflammation in BV-2 cells by inhibiting ERK1/2, JNK1/2 and NFKB signaling pathways. Int J Mol Sci 17:190. https://doi.org/10. 3390/ijms 17020190

Lim GE, Huang GJ, Flora N, LeRoith D, Rhodes CJ, Brubaker PL (2009) Insulin regulates glucagon-like peptide-1 secretion from the enteroendocrine L cell. Endocrinology 150:580-591. https://doi. org/10.1210/en.2008-0726

Litvak DA, Hellmich MR, Evers BM, Banker NA, Townsend CM Jr (1998) Glucagon-like peptide 2 is a potent growth factor for small intestine and colon. J Gastrointest Surg 2:146-150. https://doi.org/ 10.1016/S1091-255X(98)80005-X

Lund A, Vilsboll T, Bagger JI et al (2011) The separate and combined impact of the intestinal hormones, GIP, GLP-1, and GLP-2, on glucagon secretion in type 2 diabetes. Am J Physiol Endocrinol Metab 300:E1038-E1046. https://doi.org/10.1152/ajpendo.00665.2010

Marguet D, Baggio L, Kobayashi T, Bernard AM, Pierres M, Nielsen PF, Ribel U, Watanabe T, Drucker DJ, Wagtmann N (2000) Enhanced insulin secretion and improved glucose tolerance in mice lacking CD26. Proc Natl Acad Sci 97:6874-6879. https://doi.org/10.1073/ pnas. 120069197

Martin GR, Beck PL, Sigalet DL (2006) Gut hormones, and short bowel syndrome: the enigmatic role of glucagon-like peptide-2 in the regulation of intestinal adaptation. World J Gastroenterol 12:41174129

Mayo BJ, Stringer AM, Bowen JM, Bateman EH, Keefe DM (2017) Irinotecan-induced mucositis: the interactions and potential role of GLP-2 analogues. Cancer Chemother Pharmacol 79:233-249

Mimura $\mathrm{S}$, Ando $\mathrm{T}$, Ishiguro $\mathrm{K}$, Maeda $\mathrm{O}$, Watanabe $\mathrm{O}$, Ujihara $\mathrm{M}$, Hirayama Y, Morise K, Maeda K, Matsushita M, Funasaka K, Nakamura M, Miyahara R, Ozaki N, Goto H (2013) Dipeptidyl peptidase-4 inhibitor anagliptin facilitates restoration of dextran sulfate sodium-induced colitis. Scand J Gastroenterol 48:1152-1159. https://doi.org/10.3109/00365521.2013.832366

Molodecky NA, Soon IS, Rabi DM et al (2012) Increasing incidence and prevalence of the inflammatory bowel diseases with time, based on systematic review. Gastroenterology 142:46-54.e42. https://doi.org/ 10.1053/j.gastro.2011.10.001

Moran GW, Leslie FC, McLaughlin JT (2013) Crohn's disease affecting the small bowel is associated with reduced appetite and elevated levels of circulating gut peptides. Clin Nutr 32:404-411. https:// doi.org/10.1016/j.clnu.2012.08.024

Palnaes Hansen C, Andreasen JJ, Holst JJ (1997) The release of gastric inhibitory peptide, glucagon-like peptide-I, and insulin after oral glucose test in colectomized subjects. Scand J Gastroenterol 32: 473-477

Perry T (2002) Protection and reversal of excitotoxic neuronal damage by glucagon-like peptide-1 and exendin-4. J Pharmacol Exp Ther 302: 881-888. https://doi.org/10.1124/jpet.102.037481

Qi K-K, Lv J-J, Wu J, Xu Z-W (2017) Therapeutic effects of different doses of polyethylene glycosylated porcine glucagon-like peptide-2 on ulcerative colitis in male rats. BMC Gastroenterol 17:34. https:// doi.org/10.1186/s12876-017-0593-x

Radel JA, Pender DN, Shah SA (2019) Dipeptidyl peptidase-4 inhibitors and inflammatory bowel disease risk: a meta-analysis. Ann Pharmacother 106002801982785:697-704. https://doi.org/10. $1177 / 1060028019827852$

Robertson MD, Livesey G, Morgan LM, Hampton SM, Mathers JC (1999) The influence of the colon on postprandial glucagon-like 
peptide 1 (7-36) amide concentration in man. J Endocrinol 161:2531

Román ALS, Muñoz F (2011) Comorbidity in inflammatory bowel disease. World J Gastroenterol 17:2723-2733. https://doi.org/10.3748/ wjg.v17.i22.2723

Sałaga M, Sobczak M, Fichna J (2013) Inhibition of proteases as a novel therapeutic strategy in the treatment of metabolic, inflammatory and functional diseases of the gastrointestinal tract. Drug Discov Today 18:708-715

Salaga M, Mokrowiecka A, Zielinska M, Malecka-Panas E, Kordek R, Kamysz E, Fichna J (2017) New peptide inhibitor of dipeptidyl peptidase IV, EMDB-1 extends the half-life of GLP-2 and attenuates colitis in mice after topical administration. J Pharmacol Exp Ther 363:92-103. https://doi.org/10.1124/jpet.117.242586

Salaga M, Binienda A, Draczkowski P, Kosson P, Kordek R, Jozwiak K, Fichna J (2018) Novel peptide inhibitor of dipeptidyl peptidase IV (Tyr-Pro-D-Ala-NH2) with anti-inflammatory activity in the mouse models of colitis. Peptides 108:34-45. https://doi.org/10.1016/j. peptides.2018.08.011

Schmidt PT, Hartmann B, Bregenholt S et al (2000) Deficiency of the intestinal growth factor, glucagon-like peptide 2 , in the colon of SCID mice with inflammatory bowel disease induced by transplantation of CD4+ T cells. Scand J Gastroenterol 35:522-527. https:// doi.org/10.1080/003655200750023796

Schmidt PT, Ljung T, Hartmann B, Hare KJ, Holst JJ, Hellström PM (2005) Tissue levels and post-prandial secretion of the intestinal growth factor, glucagon-like peptide-2, in controls and inflammatory bowel disease: comparison with peptide YY. Eur J Gastroenterol Hepatol 17:207-212. https://doi.org/10.1097/00042737200502000-00012

Siczek K, Zatorski H, Chmielowiec-Korzeniowska A, Kordek R, Tymczyna L, Fichna J (2017) Evaluation of anti-inflammatory effect of silver-coated glass beads in mice with experimentally induced colitis as a new type of treatment in inflammatory bowel disease. Pharmacol Reports 69:386-392. https://doi.org/10.1016/j.pharep. 2017.01.003

Sigalet DL (2018) Advances in glucagon like peptide-2 therapy. Physiology, current indications and future directions. Semin Pediatr Surg 27:237-241. https://doi.org/10.1053/j.sempedsurg. 2018.07.008

Sigalet DL, Wallace LE, Holst JJ, Martin GR, Kaji T, Tanaka H, Sharkey KA (2007) Enteric neural pathways mediate the anti-inflammatory actions of glucagon-like peptide 2. Am J Physiol Liver Physiol 293: G211-G221. https://doi.org/10.1152/ajpgi.00530.2006

Singh S, Dulai PS, Zarrinpar A, Ramamoorthy S, Sandborn WJ (2017) Obesity in IBD: epidemiology, pathogenesis, disease course and treatment outcomes. Nat Rev Gastroenterol Hepatol 14:110-121

Sobczak M, Fabisiak A, Murawska N, Wesołowska E, Wierzbicka P, Wlazłowski M, Wójcikowska M, Zatorski H, Zwolińska M, Fichna J (2014) Current overview of extrinsic and intrinsic factors in etiology and progression of inflammatory bowel diseases. Pharmacol Reports 66:766-775. https://doi.org/10.1016/j.pharep. 2014.04.005

Stallmach A, Hagel S, Bruns T (2010) Adverse effects of biologics used for treating IBD. Best Pract Res Clin Gastroenterol 24:167-182. https://doi.org/10.1016/j.bpg.2010.01.002

van der Valk ME, Mangen M-JJ, Severs M, van der Have M, Dijkstra G, van Bodegraven AA, Fidder HH, de Jong DJ, van der Woude CJ, Romberg-Camps MJL, Clemens CHM, Jansen JM, van de Meeberg PC, Mahmmod N, van der Meulen-de Jong AE, Ponsioen CY, Bolwerk C, Vermeijden JR, Siersema PD, Leenders M, Oldenburg $\mathrm{B}$, COIN study group and the Dutch Initiative on Crohn and Colitis (2016) Evolution of costs of inflammatory bowel disease over two years of follow-up. PLoS One 11:e0142481. https://doi.org/10. 1371/journal.pone.0142481

Worthington JJJ (2015) The intestinal immunoendocrine axis: novel cross-talk between enteroendocrine cells and the immune system during infection and inflammatory disease: figure 1. Biochem Soc Trans 43:727-733. https://doi.org/10.1042/BST20150090

Xiao Q, Boushey RP, Cino M, Drucker DJ, Brubaker PL (2000) Circulating levels of glucagon-like peptide-2 in human subjects with inflammatory bowel disease. Am J Physiol - Regul Integr Comp Physiol 278:R1057-R1063. https://doi.org/10.1152/ajpregu.2000. 278.4.R1057

Yang J, Campitelli J, Hu G, Lin Y, Luo J, Xue C (2007) Increase in DPPIV in the intestine, liver and kidney of the rat treated with high fat diet and streptozotocin. Life Sci 81:272-279. https://doi.org/10. 1016/j.lfs.2007.04.040

Yang PY, Zou H, Lee C, Muppidi A, Chao E, Fu Q, Luo X, Wang D, Schultz PG, Shen W (2018) Stapled, long-acting glucagon-like peptide 2 analog with efficacy in dextran sodium sulfate induced mouse colitis models. J Med Chem 61:3218-3223. https://doi.org/10.1021/ acs.jmedchem. $7 \mathrm{~b} 00768$

Yazbeck R, Abbott CA, Howarth GS (2010a) The use of GLP-2 and related growth factors in intestinal diseases. Curr Opin Investig Drugs 11:440-446

Yazbeck R, Sulda ML, Howarth GS, Bleich A, Raber K, von Hörsten S, Holst JJ, Abbott CA (2010b) Dipeptidyl peptidase expression during experimental colitis in mice. Inflamm Bowel Dis 16:1340-1351. https://doi.org/10.1002/ibd.21241

Yusta B, Baggio LL, Koehler J, Holland D, Cao X, Pinnell LJ, JohnsonHenry KC, Yeung W, Surette MG, Bang KWA, Sherman PM, Drucker DJ (2015) GLP-1R agonists modulate enteric immune responses through the intestinal intraepithelial lymphocyte GLP-1R. Diabetes 64:2537-2549. https://doi.org/10.2337/db14-1577

Yusta B, Matthews D, Flock GB, Ussher JR, Lavoie B, Mawe GM, Drucker DJ (2017) Glucagon-like peptide-2 promotes gallbladder refilling via a TGR5-independent, GLP-2R-dependent pathway. Mol Metab 6:503-511. https://doi.org/10.1016/j.molmet.2017.03. 006

Zatorski H, Sałaga M, Zielińska M et al (2015) Experimental colitis in mice is attenuated by topical administration of chlorogenic acid. Naunyn Schmiedeberg's Arch Pharmacol 388:643-651. https://doi. org/10.1007/s00210-015-1110-9

Zhang Q, Liu M, Li S, Xu Z, Wang J, Wang Y, Fei Z, Huang W, Sun H (2018) Oral Bifidobacterium longum expressing GLP-2 improves nutrient assimilation and nutritional homeostasis in mice. $\mathrm{J}$ Microbiol Methods 145:87-92. https://doi.org/10.1016/j.mimet. 2018.01.002

Zhong J, Rao X, Deiuliis J, Braunstein Z, Narula V, Hazey J, Mikami D, Needleman B, Satoskar AR, Rajagopalan S (2013) A potential role for dendritic cell/macrophage-expressing DPP4 in obesity-induced visceral inflammation. Diabetes 62:149-157. https://doi.org/10. 2337/db12-0230

Zhong J, Maiseyeu A, Davis SN, Rajagopalan S (2015) DPP4 in cardiometabolic disease: recent insights from the laboratory and clinical trials of DPP4 inhibition. Circ Res 116:1491-1504

Zietek T, Rath E (2016) Inflammation meets metabolic disease: gut feeling mediated by GLP-1. Front Immunol 7:154

Zietek T, Waldschmitt N, Rath E (2017) Role of incretin hormones in bowel diseases. Endocrine Development, In, pp 49-73

Publisher's note Springer Nature remains neutral with regard to jurisdictional claims in published maps and institutional affiliations. 